\title{
A novel method for estimating shortwave direct radiative effect of above-cloud aerosols using CALIOP and MODIS data
}

\author{
Z. Zhang ${ }^{1,2}$, K. Meyer ${ }^{3,4}$, S. Platnick ${ }^{4}$, L. Oreopoulos ${ }^{4}$, D. Lee ${ }^{4,5}$, and H. Yu ${ }^{4,6}$ \\ ${ }^{1}$ Department of Physics, University of Maryland, Baltimore County (UMBC), Baltimore, MD, USA \\ ${ }^{2}$ Joint Center Earth Systems \& Technology (JCET), UMBC, Baltimore, MD, USA \\ ${ }^{3}$ Goddard Earth Sciences Technology and Research (GESTAR), Universities Space Research Association, \\ Columbia, MD, USA \\ ${ }^{4}$ NASA Goddard Space Flight Center, Greenbelt, MD, USA \\ ${ }^{5}$ Goddard Earth Sciences Technology and Research (GESTAR), Morgan State University, Baltimore, MD, USA \\ ${ }^{6}$ Earth System Science Interdisciplinary Center, University of Maryland, College Park, MD, USA
}

Correspondence to: Z. Zhang (zhibo.zhang@umbc.edu)

Received: 28 October 2013 - Published in Atmos. Meas. Tech. Discuss.: 15 November 2013

Revised: 24 April 2014 - Accepted: 6 May 2014 - Published: 19 June 2014

\begin{abstract}
This paper describes an efficient and unique method for computing the shortwave direct radiative effect (DRE) of aerosol residing above low-level liquid-phase clouds using CALIOP (Cloud-Aerosol Lidar with Orthogonal Polarization) and MODIS (Moderate Resolution Imaging Spectroradiometer) data. It addresses the overlap of aerosol and cloud rigorously by utilizing the joint histogram of cloud optical depth and cloud top pressure while also accounting for subgrid-scale variations of aerosols. The method is computationally efficient because of its use of grid-level cloud and aerosol statistics, instead of pixel-level products, and a precomputed look-up table based on radiative transfer calculations. We verify that for smoke and polluted dust over the southeastern Atlantic Ocean the method yields a seasonal mean instantaneous (approximately 13:30 local time) shortwave DRE of above-cloud aerosol (ACA) that generally agrees with a more rigorous pixel-level computation within $4 \%$. We also estimate the impact of potential CALIOP aerosol optical depth (AOD) retrieval bias of ACA on DRE. We find that the regional and seasonal mean instantaneous DRE of ACA over southeastern Atlantic Ocean would increase, from the original value of $6.4 \mathrm{~W} \mathrm{~m}^{-2}$ based on operational CALIOP AOD to $9.6 \mathrm{~W} \mathrm{~m}^{-2}$ if CALIOP AOD retrievals are biased low by a factor of 1.5 (Meyer et al., 2013) and further to $30.9 \mathrm{~W} \mathrm{~m}^{-2}$ if CALIOP AOD retrievals are biased low by a factor of 5 as suggested in Jethva et al. (2014). In contrast, the instantaneous ACA radiative
\end{abstract}

forcing efficiency (RFE) remains relatively invariant in all cases at about $53 \mathrm{~W} \mathrm{~m}^{-2} \mathrm{AOD}^{-1}$, suggesting a near-linear relation between the instantaneous RFE and AOD. We also compute the annual mean instantaneous shortwave DRE of light-absorbing aerosols (i.e., smoke and polluted dust) over global oceans based on 4 years of CALIOP and MODIS data. We find that given an above-cloud aerosol type the optical depth of the underlying clouds plays a larger role than above-cloud AOD in the variability of the annual mean shortwave DRE of above-cloud light-absorbing aerosol. While we demonstrate our method using CALIOP and MODIS data, it can also be extended to other satellite data sets.

\section{Introduction}

The shortwave direct radiative effect (DRE) of aerosols at the top of the atmosphere (TOA) is strongly dependent on the reflectance of the underlying surface. Over dark surfaces (e.g., ocean, vegetated land), the scattering effect of aerosols is generally dominant, leading to negative DRE (i.e., cooling) at TOA (Yu et al., 2006). In contrast, when light-absorbing aerosols occur above clouds or other bright surfaces (such as snow, ice, and desert), aerosol absorption is significantly amplified by cloud or surface reflection, offsetting or even exceeding the scattering effect of the aerosol, leading to a less negative or even positive (i.e., warming) TOA DRE (Abel et 
al., 2005; Keil and Haywood, 2003; Twomey, 1977). Therefore, in order to understand the full complexity of aerosol radiative effects on climate, it is important to quantify the DRE under both clear-sky and cloudy-sky conditions. The DRE of aerosols in clear-sky regions has been extensively studied and is relatively well constrained based on advanced satellite remote sensing measurements acquired in the last decade (Yu et al., 2006). However, current model simulations show a large intermodel spread in cloudy-sky DRE (Schulz et al., 2006), which results from intermodel differences in both aerosol and cloud properties (Schulz et al., 2006; Stier et al., 2013). Therefore, there is a clear need for an observational constraint on the DRE of above-cloud aerosol (ACA).

Recent advances in satellite remote sensing techniques have provided an unprecedented opportunity for studying the DRE of ACA. In particular, the availability of measurements from the space-borne Cloud-Aerosol Lidar with Orthogonal Polarization (CALIOP) sensor onboard NASA's Cloud-Aerosol Lidar and Infrared Pathfinder Satellite Observations (CALIPSO) satellite has provided a revolutionary global view of the vertical distribution of aerosols and clouds (e.g., Winker et al., 2013). Using CALIOP aerosol and cloud layer products, Devasthale and Thomas (2011) found frequent occurrences of aerosols residing above lowlevel clouds in several regions of the globe. In particular, they found a high frequency of smoke occurrence over low clouds in the southeastern Atlantic, western coasts of South America (e.g., Colombia, Ecuador, and Peru) and southern Asia. These authors also found a high frequency of natural and polluted dust aerosols overlapping low clouds off the western coast of Saharan Africa in boreal summer and over boundary layer clouds in the eastern coast of China in boreal spring (see Fig. 3 of Devasthale and Thomas, 2011).

CALIOP measurements of ACA properties, in combination with satellite cloud products from, for example, the Moderate Resolution Imaging Spectroradiometer (MODIS), have been used in several recent studies to derive the DRE of ACA with radiative transfer simulations (e.g., Chand et al., 2009; Costantino and Bréon, 2013b; Meyer et al., 2013; Oikawa et al., 2013). Chand et al. (2009) used CALIOP above-cloud AOD retrievals (Chand et al., 2008) and TerraMODIS cloud products, both aggregated to $5^{\circ}$ gridded monthly means, to calculate the radiative effects of smoke transported above the low-level stratocumulus deck in the southeastern Atlantic. The spatiotemporal aggregation of both CALIOP and MODIS data to coarse-gridded monthly means obscures the potential influence of cloud and aerosol variability on the DRE. In particular, using the grid-box mean cloud optical depth for DRE calculation might lead to biases in DRE due to the plane-parallel albedo bias (Oreopoulos et al., 2007). Moreover, the MODIS level-3 aggregation algorithm samples all liquid water clouds, regardless of whether or not there is an aerosol layer above clouds. As a result, the total population of liquid water clouds in the MODIS level-3 products (daily or monthly) may be significantly different from that of the below-aerosol-only cloud population. Therefore, using level-3 MODIS products without distinguishing below-aerosol-only from total cloud population can potentially lead to significant errors. The problem could be further complicated by biases in MODIS cloud retrievals associated with the presence of overlying light-absorbing aerosols. When a cloud pixel is contaminated by overlying light-absorbing aerosols the MODIS cloud optical depth (COD) retrieval is generally biased low (e.g., Coddington et al., 2010; Haywood et al., 2004; Jethva et al., 2013; Wilcox, 2010), an effect not considered in most previous studies (e.g., Chand et al., 2009; Costantino and Bréon, 2013b; Oikawa et al., 2013). Most recently however, Meyer et al. (2013) collocated CALIOP above-cloud AOD and Aqua-MODIS cloud properties at the pixel level, and the DRE was then computed at these individual collocated pixels. They found that correcting the MODIS COD bias due to ACA contamination leads to a more positive ACA DRE. Such rigorous collocation has obvious advantages as it takes into account the subgrid variability of clouds and aerosols, but is however computationally expensive since it requires large amounts of pixel-level data that make global scale and multiyear studies challenging.

The objective of this paper is to describe a novel method for computing the DRE of ACA. This method attempts to balance the need for computational efficiency with the need for rigorous treatment of aerosol-cloud overlap and smallscale variability of aerosol and clouds. Our method has several unique features: (1) it takes subgrid-scale cloud and aerosol variation into account in DRE computations, (2) it treats the overlap of aerosol and cloud rigorously by utilizing the joint histogram of COD and cloud top pressure (CTP) in the MODIS level-3 product, and (3) it is computationally efficient because of the use of a precomputed look-up table of ACA DRE.

In the following sections, we briefly introduce the CALIOP and MODIS data used (Sect. 2), describe the key assumptions and features of the novel method (Sect. 3), validate it through comparison with pixel-level computations as in Meyer et al. (2013) (Sect. 4), and conclude with a summary and discussion (Sect. 5).

\section{Satellite data}

In Meyer et al. (2013), the MODIS level-2 cloud product is collocated with the CALIOP level-2 aerosol product for every pixel along the CALIOP track and the computation of instantaneous DRE is performed pixel by pixel. Then, the pixel-level DRE results are aggregated on a latitudelongitude grid for climatological study. If only the gridlevel DRE is of interest, the pixel-by-pixel computation of DRE may not be efficient because of redundant computations. For example, if two pixels with the same above-cloud AOD and below-cloud COD occur within the same grid box, 
they evidently have the same ACA DRE, but the radiative transfer computation is nevertheless performed twice in the pixel-by-pixel method. As shown in Sect. 3, a more efficient way is to compute the DRE statistically using the probability density function (PDF) of above-cloud AOD and belowcloud COD. In this study, we use the CALIOP level-2 aerosol and cloud layer product (V3.01) to derive the statistics of ACA properties and the MODIS level-3 daily cloud product for cloud property statistics. It is important to note that our method is not limited to CALIOP and MODIS products, but is also applicable to other satellite data sets, such as above-cloud aerosol retrievals from POLDER (POLarization and Directionality of the Earth's Reflectances) (Waquet et al., 2009) and OMI (Ozone Monitoring Instrument) (Torres et al., 2012), and cloud retrievals from ISCCP (International Satellite Cloud Climatology Project) (Rossow and Schiffer, 1999) and SEVIRI (Spinning Enhanced Visible and Infrared Imager) (Schulz et al., 2009).

\subsection{CALIOP level-2 aerosol and cloud layer products}

Since its launch in 2006, the space-borne lidar CALIOP has continuously acquired, with near global (albeit instantaneously sparse) coverage, attenuated backscatter measurements at 532 and $1064 \mathrm{~nm}$, including linear depolarization information at $532 \mathrm{~nm}$ (Winker et al., 2009). The CALIOP level-2 retrieval algorithm consists of several steps. First, a "feature finder" algorithm and cloud-aerosol discrimination (CAD) algorithm are used to detect aerosol and cloud layers, and record their top and bottom heights and layerintegrated properties (Vaughan et al., 2009). Second, the detected aerosol layers are further classified into six subtypes (i.e., polluted continental, biomass burning, desert dust, polluted dust, clean continental and marine) (Omar et al., 2009) and the detected cloud layers are assigned different thermodynamic phases (Hu et al., 2007a) based on the observed backscatter, color ratio and depolarization ratio. Third, a priori lidar ratios, preselected based on aerosol subtype and cloud phase, are used to derive the extinction of an aerosol or cloud layer from the attenuated backscatter profile (Young and Vaughan, 2008).

In this study, we use CALIOP level-2 version 3.01 aerosol and cloud layer products at a nominal $5 \mathrm{~km}$ horizontal resolution (i.e., CAL_LID_L2_05kmALay and CAL_LID_L2_05kmCLay) for aerosol-cloud overlap detection, and for information on aerosol layer properties, including type, aerosol optical depth (AOD), and layer top and bottom height. In addition to physical properties, the CALIOP layer products also provide various metrics and flags on data quality assurance. These include CAD score (Liu et al., 2009), horizontal averaging scale, extinction quality control (QC) flag, and estimated uncertainty of layer AOD. In this study, we apply these metrics following best practices provided by the CALIPSO science team to screen for reliable retrievals (e.g., Winker et al., 2013) (see Table 1).
Table 1. Quality control metrics used for screening the CALIOP aerosol layer product.

\begin{tabular}{ll}
\hline & Criterion \\
\hline CAD_score & $<-30$ \\
Horizontal_averaging & $<20 \mathrm{~km}$ \\
Extinction_QC_532 & 0 or 1 \\
Feature_optical_depth_uncertainty_532 & $<-99.5$ \\
\hline
\end{tabular}

It should be noted here that the current version of CALIOP operational aerosol retrieval algorithm (V3.01) appears to significantly underestimate the AOD of above-cloud aerosol layer according to recent studies (Jethva et al., 2014; Kacenelenbogen et al., 2013, 2011; Liu et al., 2013; Torres et al., 2013; Waquet et al., 2013b). The main reason is that after strong attenuation by the upper part of an aerosol layer, the $532 \mathrm{~nm}$ attenuated backscatter of the lower part of aerosol layer is often too small (Torres et al., 2013). As a result, the current CALIOP feature detection algorithm often cannot resolve the full depth of the aerosol layer, leading to low biases in retrieved AOD (Jethva et al., 2014; Liu et al., 2013; Torres et al., 2013). This issue is more acute for smoke than dust because smoke has a much larger lidar ratio. At the moment, the CALIOP operational team is investigating the possibility of using the algorithm described in Chand et al. (2008) and $\mathrm{Hu}$ et al. (2007b) for ACA retrievals (Liu et al., 2013). This alternate method utilizes the reflected lidar signal from the bright cloud layer underneath to derive the two-way transmittance and thereby the AOD of the ACA layer. Because the backscatter of a cloud layer is usually very strong, the two-way transmittance method is less affected by the strong attenuation of the ACA layer and is therefore expected to alleviate the aforementioned problem. Lidar based AOD retrievals are also known to suffer from other issues, such as the background solar noise during daytime. These issues are beyond the scope of this study, but are nevertheless discussed in the uncertainty analysis of Sect. 3.4.

In addition to retrieval errors and uncertainties, another limitation of CALIOP data is the small sampling rate (i.e., only along track). In order to compute the DRE of ACA over a given latitude-longitude grid box, we assume that the aerosol property statistics retrieved by CALIOP along its narrow track represent the statistics over the whole grid box, i.e., that AOD PDFs are identical. This assumption constitutes an uncertainty in our DRE computation. Due to a lack of satellite-based wide-swath ACA data sets, however, it is difficult to determine the size of this uncertainty. Recently, several novel methods have been developed to retrieve ACA properties from passive sensor observations (Jethva et al., 2013; Torres et al., 2012; Waquet et al., 2009, 2013a), which will help improve our understanding of the subgrid ACA variability when they become available to public. 
Finally, we emphasize two more points. First, none of the aforementioned problems with CALIOP data, e.g., smoke AOD bias, retrieval uncertainties, and small sampling rate, are unique to our method. Any method that uses CALIOP data faces the same challenges. Second, our method is not limited only to CALIOP data. We choose to use the CALIOP product in this study solely because it is the only publicly available ACA product at the moment. Our method can also be applied to other ACA retrieval products based on, for example, POLDER (Waquet et al., 2009), MODIS (Jethva et al., 2013), and OMI (Torres et al., 2012) observations when they become available to the public. In fact, as discussed later, the advantage of our method in terms of computational efficiency is even greater when applied on retrievals from passive sensors.

\subsection{MODIS daily level-3 cloud property product}

This study computes the grid-level ACA DRE using the statistics of aerosol and cloud properties, instead of pixelby-pixel computation as in Meyer et al. (2013). We use the collection 5 (C5) Aqua-MODIS level-3 daily gridded atmosphere product MYD08_D3 for the statistics of cloud properties and other parameters, such as solar zenith angle, needed for ACA DRE computations.

The MODIS level-3 (i.e., grid level) product contains statistics computed from a set of level-2 (i.e., pixel level) MODIS granules. As summarized in Platnick et al. (2003), the operational level-2 MODIS cloud product provides cloud masking (Ackerman et al., 1998), cloud top height retrieval based on $\mathrm{CO}_{2}$ slicing or the infrared window method (Menzel et al., 1983), cloud top thermodynamic phase determination (Menzel et al., 2006), and cloud optical and microphysical property retrieval based on the bispectral solar reflectance method (Nakajima and King, 1990). In addition to these cloud parameters, the level-2 products also provide pixellevel runtime quality assessment (QA) information, which includes product quality as well as processing path information. All MODIS level-2 atmosphere products, including the cloud, aerosol and water vapor products, are aggregated to $1^{\circ}$ spatial resolution on a daily (product name MYD08_D3 for Aqua MODIS), eight-day (MYD08_E3), and monthly (MYD08_E3) basis. Aggregations include a variety of scalar statistical information (mean, standard deviation, $\max / \mathrm{min}$ occurrences) and histograms (marginal and joint). A particularly useful level-3 cloud product for this study is the daily joint histogram of COD vs. CTP, derived using daily counts of successful daytime level-2 pixel retrievals that fall into each joint COD-CTP bin. Eleven COD bins, ranging from 0 to 100 , and 13 CTP bins, ranging from 200 to $1000 \mathrm{mb}$, comprise the histogram. As discussed below, the COD-CTP joint histogram allows for identification of the portion of the cloud population that lies beneath the aerosol layer found by CALIOP, as well as the corresponding COD probability distribution needed for DRE estimation. In addition to the
COD-CTP joint histogram, we also use the gridded mean solar and sensor zenith angles for calculating DRE and correcting the COD bias due to the presence of ACA.

It should be noted that the level-3 daily product MYD08_D3 contains statistics computed from a set of level2 MODIS granules that theoretically span a $24 \mathrm{~h}$ interval (Hubanks et al., 2008). However, for cloud parameters retrieved only during daytime, such as COD and cloud droplet effective radius (CER), only daytime level-2 files are used to compute the level-3 daily statistics. These are called daytime only SDSs (scientific data sets) in level-3 products. Strictly speaking, the daytime only SDSs of only those $1^{\circ}$ grid cells between approximately $23^{\circ} \mathrm{N}$ and $23^{\circ} \mathrm{S}$ come from a single MODIS overpass. The tropical southeastern Atlantic region, where transported smoke aerosols are often observed above low-level stratocumulus clouds, is well within this range (about $10^{\circ} \mathrm{N}-30^{\circ} \mathrm{S}$ see Fig. 3). The COD statistics in the MYD08_D3 product for this region are therefore derived from a single Aqua-MODIS overpass that can be collocated with CALIOP observations (see Sect. 3.1 for details on collocation). The DRE computed based on the collocated data set is therefore instantaneous DRE at Aqua crossing time (13:30 LT, local time) that are directly comparable to the pixel-by-pixel results in Meyer et al. (2013). Poleward of $23^{\circ}$, MYD08_D3 statistics are derived from averaging several overlapping orbits approximately $100 \mathrm{~min}$ apart (Hubanks et al., 2008). As a result, strictly speaking the DRE computed for mid- and high-latitude regions based on MYD08_D3 data is not instantaneous DRE. We emphasize that this is not a limitation of our method, but an inherent characteristic of the MODIS level-3 product. Finally, it needs to be noted that MODIS cloud property products are subject to retrieval uncertainties caused by various factors such as subpixel inhomogeneity, 3-D radiative transfer effects and presence of precipitation in clouds (Zhang, 2013; Zhang and Platnick, 2011; Zhang et al., 2012). The uncertainties in cloud property retrieval could translate to uncertainty in the ACA DRE computation, which will be investigated in future studies.

\section{Methodology}

\subsection{Theoretical basis}

As in previous investigations (e.g., Chand et al., 2008, 2009; Costantino and Bréon, 2013b; Meyer et al., 2013), we focus on the simplest case of overlapping aerosol and cloud, i.e., a single layer of aerosol overlying a single layer of lowlevel liquid-phase clouds, which is commonly observed in many regions of the globe (Devasthale and Thomas, 2011). More complex situations certainly exist, such as an aerosol layer located in between high and low clouds, or an aerosol layer overlying multiple layers of clouds. However, identification of such situations are either beyond the detection 


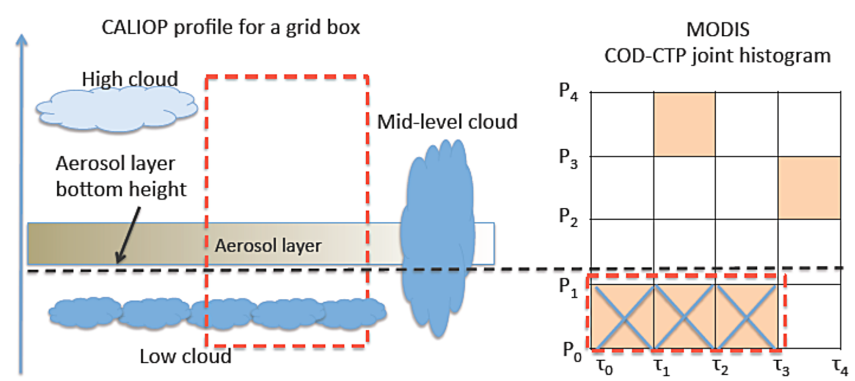

Figure 1. A schematic example to illustrate how CALIOP aerosol layer height information is used in our method to determine the population of liquid-phase clouds below the aerosol layer in the MODIS COD-CTP joint histogram.

capabilities of CALIOP or relatively rare (Devasthale and Thomas, 2011). As such, they are not considered here and left for future research.

To illustrate the theoretical foundation of the method, consider the schematic example in Fig. 1. For a given grid box (e.g., $1^{\circ} \times 1^{\circ}$ in case of MODIS level-3 data), the gridded mean instantaneous broadband shortwave DRE $\left(\langle\mathrm{DRE}\rangle_{\mathrm{ACA}}\right)$ averaged over all ACA pixels within the grid box is given as

$$
\langle\mathrm{DRE}\rangle_{\mathrm{ACA}}=\int_{0}^{\infty} \int_{0}^{\infty} \operatorname{DRE}\left(\tau_{\mathrm{c}}, \tau_{\mathrm{a}}\right) p\left(\tau_{\mathrm{c}}, \tau_{\mathrm{a}}\right) d \tau_{\mathrm{c}} d \tau_{\mathrm{a}},
$$

where $p\left(\tau_{\mathrm{c}}, \tau_{\mathrm{a}}\right)$ is the joint PDF of the above-cloud AOD at $532 \mathrm{~nm}\left(\tau_{\mathrm{a}}\right)$ and below-aerosol COD $\left(\tau_{\mathrm{c}}\right)$ of ACA pixels. We note that, in addition to $\tau_{\mathrm{a}}$, DRE also depends on the spectral variation of aerosol and cloud optical depth, spectral single scattering albedo and asymmetry factor, wavelength dependencies not explicitly shown in this equation. These properties are computed using a Mie scattering code (Wiscombe, 1980) based on the aerosol model described in Meyer et al. (2013). The dependencies on solar zenith angle, surface reflectance, cloud particle effective radius, and atmospheric profile are also omitted from the equation; solar zenith angle and surface reflectance are expected to have only minor variation within the grid box, while the impact of cloud particle effective radius and atmospheric profile on shortwave DRE is relatively small. Since $p\left(\tau_{\mathrm{c}}, \tau_{\mathrm{a}}\right)$ describes the covariation of aerosols and clouds for the ACA pixels, it should ideally be derived from collocated CALIOP aerosol and MODIS cloud retrievals at pixel level as in Meyer et al. (2013). However, this requires large amounts of pixel-level data. Therefore, pixel-level collocation and radiative transfer simulation are too computationally expensive and cumbersome for multiyear global studies.

A key assumption in our method, which allows us to avoid tedious pixel-level collocation, is that the subgrid level instantaneous spatial distribution of above-cloud AOD is statistically independent from the subgrid level instantaneous spatial distribution of below-aerosol COD. Under this assumption, $p\left(\tau_{\mathrm{c}}, \tau_{\mathrm{a}}\right)=p\left(\tau_{\mathrm{c}}\right) \cdot p\left(\tau_{\mathrm{a}}\right)$ and Eq. (1) reduces to

$$
\langle\mathrm{DRE}\rangle_{\mathrm{ACA}}=\int_{0}^{\infty}\left[\int_{0}^{\infty} \operatorname{DRE}\left(\tau_{\mathrm{c}}, \tau_{\mathrm{a}}\right) p\left(\tau_{\mathrm{c}}\right) d \tau_{\mathrm{c}}\right] p\left(\tau_{\mathrm{a}}\right) d \tau_{\mathrm{a}},
$$

where $p\left(\tau_{\mathrm{c}}\right)$ and $p\left(\tau_{\mathrm{a}}\right)$ are the PDF of instantaneous belowaerosol COD $\tau_{\mathrm{c}}$ and above-cloud $\mathrm{AOD} \tau_{\mathrm{a}}$, respectively, of ACA pixels. The advantage of Eq. (2) is that it allows $p\left(\tau_{\mathrm{c}}\right)$ and $p\left(\tau_{\mathrm{a}}\right)$ to be derived separately and independently. This assumption is reasonable considering that transported ACAs and low-level boundary layer clouds are usually well separated vertically (Devasthale and Thomas, 2011) and controlled by different meteorological conditions. The potential coupling between the two is that overlying absorbing aerosols could influence the evolution of clouds through changing atmospheric stratification (Wilcox, 2010). However, a recent observational study (Costantino and Bréon, 2013a) found no correlation between above-cloud AOD and below-aerosol COD, although correlations are found between AOD and cloud droplet effect radius, as well as liquid water path. Moreover, it is important to stress that our assumption is that the instantaneous above-cloud AOD and below-aerosol COD are independent at subgrid scale. This assumption does not rule out the possibility that AOD and COD could be correlated at longer temporal (e.g., seasonal) and/or larger spatial (e.g., regional) scales through the thermodynamic and radiative coupling (Wilcox, 2010, 2012). Finally, as shown in Sect. 4, when we compare the DRE derived from pixel-level collocation (i.e., based on Eq. 1) with that from independent sampling of $p\left(\tau_{\mathrm{c}}\right)$ and $p\left(\tau_{\mathrm{a}}\right)$ (i.e., based on Eq. 2) the agreement is very good.

In our method, the PDF of above-cloud AOD $p\left(\tau_{\mathrm{a}}\right)$ is derived from the CALIOP $5 \mathrm{~km}$ aerosol and cloud layer products through the following steps: (1) for each $5 \mathrm{~km}$ CALIOP profile that falls within a given latitude-longitude grid box, we first search for an aerosol layer; (2) if an aerosol layer is detected and the quality metrics pass the quality assurance criteria summarized in Table 1, we then proceed to check for the presence of an underlying liquid-phase cloud layer within the profile using the CALIOP cloud layer product; and (3) if a cloud layer is present, the AOD of the aerosol layer is recorded for the derivation of the $p\left(\tau_{\mathrm{a}}\right)$ of the grid box. The bottom height of the aerosol layer is also recorded to derive the grid mean aerosol layer bottom height. Once all of the CALIOP profiles within the grid box are processed, we obtain the PDF of the above-cloud $\operatorname{AOD} p\left(\tau_{\mathrm{a}}\right)$ and the mean aerosol layer bottom pressure $\left\langle P_{\text {bottom }}\right\rangle$.

As schematically illustrated in Fig. 1, the PDF of belowaerosol $\operatorname{COD} p\left(\tau_{\mathrm{c}}\right)$ is derived from the joint histogram of cloud optical depth and cloud top pressure (COD-CTP joint histogram) in the MODIS daily level-3 product, using the grid-mean aerosol-layer bottom pressure $\left\langle P_{\text {bottom }}\right\rangle$ derived above. For a given grid box, we first identify the population of liquid-phase clouds below the pressure level $\left\langle P_{\text {bottom }}\right\rangle$. 
This subset, together with the $\operatorname{AOD} \operatorname{PDF} p\left(\tau_{\mathrm{a}}\right)$, is then used to calculate DRE according to Eq. (2).

In this study, we focus on the computation of instantaneous DRE. To obtain diurnally averaged DRE, technically speaking one would simply need to integrate over time the instantaneous DRE. However, it is important to note that, in addition to diurnal variation of solar zenith angle, aerosol and cloud properties may also have significant diurnal cycles. In fact, it is known that the low cloud fraction over stratocumulus regimes, such as the southeastern Atlantic region, have a strong diurnal cycle (15-35\% of diurnal mean value) driven by cloud solar absorption (Wood et al., 2002). A recent study by Min and Zhang (2014) indicates that using a constant cloud fraction based on Aqua-MODIS observations tends to result in significantly underestimated diurnal mean DRE even if the diurnal variation of solar zenith angle is considered in the computation. Therefore, the diurnal variation of cloud properties is an important factor to consider in the intercomparison of DRE computations based on different data sets and intercomparison between observational study and modeling results.

\subsection{DRE look-up tables}

To speed up calculations, we use precomputed aerosol-type specific look-up-tables (LUTs), instead of online radiative transfer computation, when deriving the DRE of ACA. The concept of our LUTs is somewhat similar to the "radiative kernels" described in Hartmann et al. (2001) and Zelinka et al. (2012) for computing cloud radiative feedbacks. The LUT for each aerosol type consists of DREs at both TOA and surface (not used in this study) for various combinations of AOD, COD, CTP and solar zenith conditions. As such, once the aerosol type and AOD are known from CALIOP and COD, CTP and solar zenith angle are known from MODIS, and the corresponding DRE can be obtained through LUT interpolation. Note that the CALIOP only provides AOD at lidar wavelengths (e.g., 532 and $1064 \mathrm{~nm}$ ) for each aerosol type. Therefore, radiative transfer model-appropriate narrowband aerosol scattering properties, namely AOD, singlescattering albedo and asymmetry factor, are needed for the development of the LUT. The current version of LUT focuses on light-absorbing aerosols (e.g., smoke and polluted dust). In order to validate our method with more rigorous pixellevel computations, we adopt the narrowband aerosol optical properties of Meyer et al. (2013), who used the same radiative transfer code, in the computation of the current LUT. The aerosol model in Meyer et al. (2013) is extended from an absorbing aerosol model developed for the MODIS Collection 5 aerosol product (MOD04) (see Table 4 of Levy et al., 2009). The MOD04 aerosol models define aerosol size distributions and refractive indices based solely on prescribed AOD at $550 \mathrm{~nm}$ (MODIS band 4; note that the absorbing aerosol model used here assumes a constant index of refraction, $1.51-0.02 i$, at all wavelengths). At $\mathrm{AOD}=0.5$

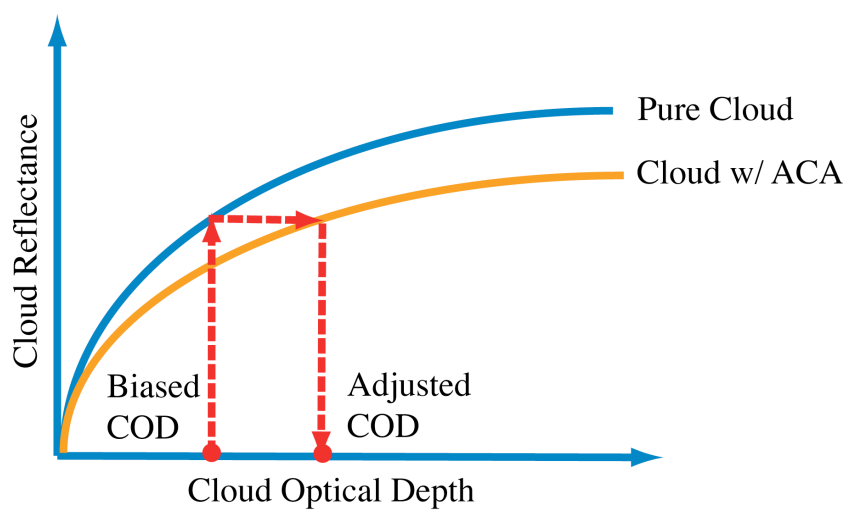

Figure 2. A schematic illustration of our fast scheme to correct the COD retrieval bias in the MODIS cloud product due to overlying aerosol contamination.

$(550 \mathrm{~nm})$, the single-scattering albedo of this model is about 0.9 over the visible spectral region (see Fig. 7 of Meyer et al., 2013), which is in the range of previously reported values (e.g., Keil and Haywood, 2003; Myhre et al., 2003). The current AOD bins (at $550 \mathrm{~nm}$ ) in the LUT range from 0.05 to 1.5 , which covers most of the above-cloud AOD observed by CALIOP. The current COD bins, logarithmically spaced, range from 0.1 to 300 . Following the MODIS level3 data, the thirteen CTP bins range from 1000 to $200 \mathrm{mb}$. The solar zenith angle bins range from 0 to $80^{\circ}$. Radiative transfer computations are carried out using the RRTM-SW (rapid radiative transfer model, shortwave) model (Clough et al., 2005; Iacono et al., 2008). Lambertian ocean surface reflectance is set to $5 \%$. Cloud droplet effective radius is fixed at $15 \mu \mathrm{m}$, which is close to the global mean value over oceans observed by MODIS (King et al., 2013). This value of effective radius is also used to convert the MODIS visible COD to liquid water path used as input to RRTM-SW. Liquid cloud optical properties are calculated internally by RRTM. For atmospheric profiles of water vapor and temperature, we use NCEP (National Centers for Environmental Prediction) R1 reanalysis data (Kistler et al., 2001) averaged both zonally and annually. Our sensitivity tests indicate that the shortwave DRE of ACA is largely insensitive to cloud effective radius or atmospheric profiles.

\subsection{Cloud optical depth correction}

As noted in previous studies (Coddington et al., 2010; e.g., Haywood et al., 2004), when a cloudy MODIS pixel is contaminated by overlying light-absorbing aerosols the COD retrieval is generally biased low. We have developed a fast COD correction scheme to account for the COD retrieval bias due to ACA in our DRE computation, which is illustrated in Fig. 2. This scheme requires both the cloud reflectance LUT for clouds without ACA, for which we use the MODIS operational LUT, and clouds with ACA, for which we use 
the one developed by Meyer et al. (2013). In the operational MODIS retrieval, the reflectance LUT of cloud without ACA is used to interpret the reflectance of all clouds, including those affected by ACA. Based on this fact, we first infer the "observed" cloud reflectance (after atmospheric correction) by interpolating the reflectance LUT of cloud without ACA corresponding to the biased COD. Then, we use the "observed" cloud reflectance and ACA-affected LUT (derived based on CALIOP AOD) to determine the corrected COD. This COD correction process is performed for every combination of COD bin in $p\left(\tau_{\mathrm{c}}\right)$ and AOD bin in $p\left(\tau_{\mathrm{a}}\right)$. In the final step we resample the corrected CODs to obtain the corrected $p\left(\tau_{\mathrm{c}}\right)$.

It should be noted that because different aerosol types may have different impacts on MODIS COD retrievals, the above COD correction process is aerosol-type dependent. In this study, we use light-absorbing aerosols as example to illustrate our method and for validation purposes we use the aerosol model developed by Meyer et al. (2013) for the development of LUTs for DRE computation and COD correction. However, the LUTs can be easily extended to other aerosol models. In fact, as part of ongoing research, we are extending our LUTs to include all six operational CALIOP aerosol models as described in Omar et al. (2009).

\subsection{Uncertainty analysis}

Several recent studies suggest that the current operational CALIOP product tends to underestimate the above-cloud AOD. Meyer et al. (2013) found that the daytime CALIOP AOD retrievals are systematically smaller than the nighttime retrievals, probably due to the daytime solar background issue. In light of this finding, Meyer et al. (2013) increased the CALIOP AOD retrievals by a factor of 1.5 to account for the impact of potential AOD bias on DRE of ACA. A more recent case study by Jethva et al. (2014) suggests that CALIOP ACA AOD retrievals are biased low by a factor of 5 or even more compared with other retrievals, although the generality of this finding needs to be further tested with larger samples. While a rigorous analysis uncertainty analysis of CALIOP AOD product is beyond the scope of this study, it is nevertheless reasonable to assume that the current CALIOP retrievals provide a lower limit to the ACA AOD. In the uncertainty analysis presented in the next section, we carry out two sensitivity tests to estimate the potential impacts of CALIOP AOD bias on DRE computation. We multiply CALIOP AOD values by a factor of 1.5 in the first test following Meyer et al. (2013) and by a factor of 5 in the second as suggested in Jethva et al. (2014).

Once the magnitude of the uncertainties in the input data is prescribed, the consequential impact on DRE can be easily estimated in our method as follows. First, in addition to the $p\left(\tau_{\mathrm{a}}\right)$ based on the original CALIOP data, we also derive the perturbed $\operatorname{PDF} \tilde{p}\left(\tau_{\mathrm{a}}\right)$ by perturbing the original data according to predefined uncertainties (i.e., by increasing the original values by a factor of 1.5 or 5). Then, the impact of input uncertainty on ACA DRE can be estimated by comparing the DREs computed with the original vs. perturbed PDF (i.e., $\langle\mathrm{DRE}\rangle_{\mathrm{ACA}}$ vs. $\langle\widetilde{\mathrm{DRE}}\rangle_{\mathrm{ACA}}$ ). Note that $\langle\mathrm{DRE}\rangle_{\mathrm{ACA}}$ and $\langle\widetilde{\mathrm{DRE}}\rangle_{\mathrm{ACA}}$ can be obtained in a single computation because they both represent integrals over $\operatorname{DRE}\left(\tau_{\mathrm{c}}, \tau_{\mathrm{a}}\right)$, only with different weights. In this regard, our method is much more efficient than the pixel-by-pixel method, in which uncertainty must be estimated by perturbing individual pixels.

\section{Implementation and validation of new DRE estimation scheme}

Each year during austral winter, dry season biomass burning activities throughout southern Africa inject large amounts of smoke into the troposphere (Eck et al., 2003; Ichoku et al., 2003; Myhre et al., 2003). Prevailing easterly winds during this season often transport the smoke to the west, off the continent, over the ocean, where extensive marine boundary layer clouds persist for most of the year. Under the descending branch of the Hadley cell, the air mass above the boundary layer is quite dry. Due to the lack of efficient wet scavenging, the transported aerosol layers can remain suspended in the atmosphere for days, creating a near-persistent smoke layer above the stratocumulus deck over the southeastern Atlantic Ocean (Chand et al., 2009; Devasthale and Thomas, 2011; Keil and Haywood, 2003; Wilcox, 2010).

To validate our method, we have compared the DRE of above-cloud light-absorbing aerosols in this region with pixel-level computations from Meyer et al. (2013). Figure 3a shows the seasonal mean (August/September 2007-2011) instantaneous TOA DRE of above-cloud smoke and polluted dust based on the pixel-level computations from Meyer et al. (2013). Figure 3b shows the corresponding instantaneous TOA aerosol radiative forcing efficiency (RFE) defined as the DRE per unit AOD. The DRE and RFE results computed using our method described in the previous section are shown in Fig. 3c and d, respectively. Evidently, both DRE and RFE computed using our new method agree closely with the pixel-level computations. Figure 4 shows the meridional mean DRE and RFE for the region using the results in Fig. 3. Not surprisingly, the outcomes of the two methods are almost identical. Note that the CODs used in the computations for Figs. 3 and 4 are directly from the MODIS products without COD correction. We have also compared the DRE and RFE from the two methods using the corrected COD and achieved again very good agreement (not shown because of close resemblance to Fig. 3 and Fig. 4). The seasonal and regional mean DRE and RFE, based on the corrected COD, from the pixel-level computation method in Meyer et al. (2013) are $6.6 \mathrm{~W} \mathrm{~m}^{-2}$ and $56 \mathrm{~W} \mathrm{~m}^{-2} \mathrm{AOD}^{-1}$, respectively (see Table 2). The corresponding values from our new method are $6.4 \mathrm{~W} \mathrm{~m}^{-2}$ and $53.8 \mathrm{~W} \mathrm{~m}^{-2} \mathrm{AOD}^{-1}$, respectively. 

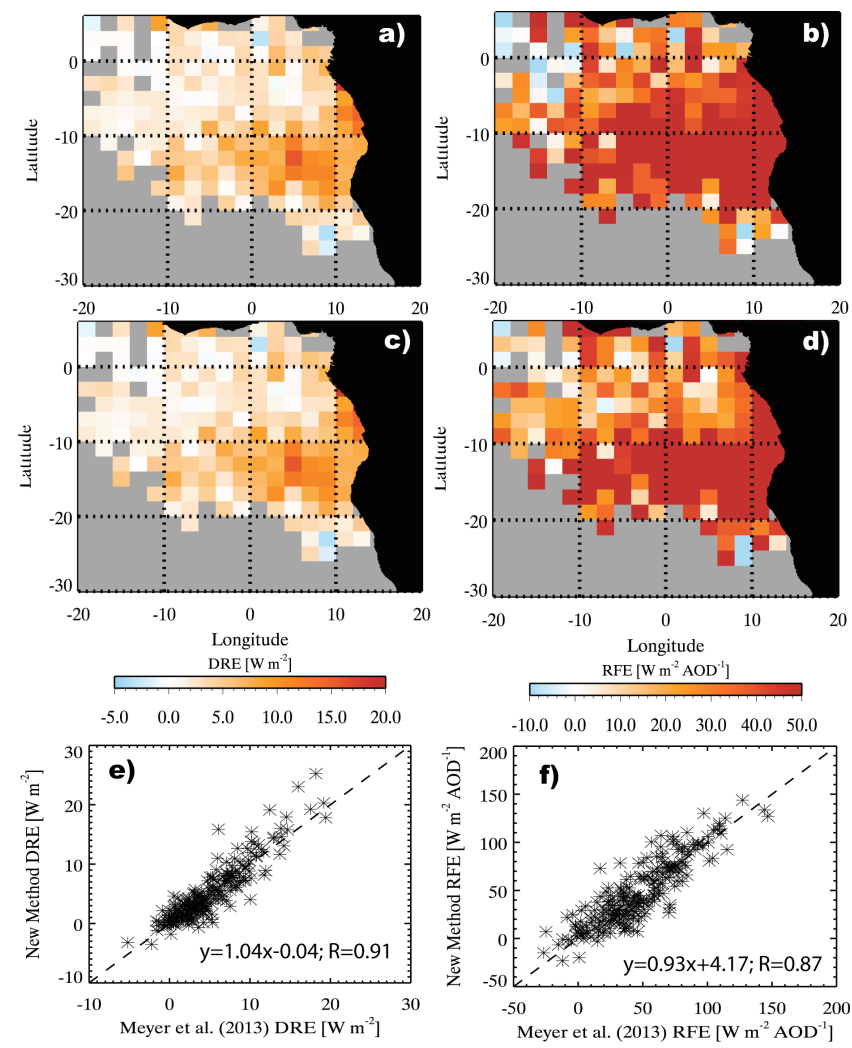

$\begin{array}{lllllll}-10.0 & 0.0 & 10.0 & 20.0 & 30.0 & 40.0 & 50.0\end{array}$

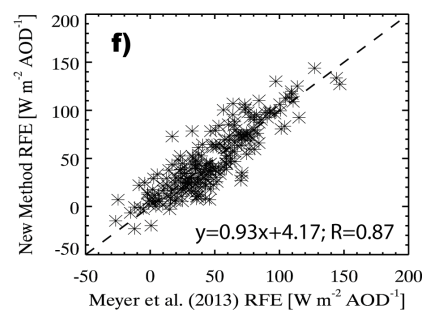

Figure 3. (a) Seasonal mean (August/September 2007-2011) instantaneous TOA DRE of above-cloud smoke and polluted dust based on the pixel-level computations from Meyer et al. (2013); (b) seasonal mean instantaneous TOA aerosol RFE (i.e., DRE per AOD) from Meyer et al. (2013); (c) same as (a), but based on the new method; (d) same as (b), but based on the new method. Scatter plot of new method vs. Meyer et al. (2013) grid-mean (e) DRE and (f) RFE.

Table 2. Regional and seasonal mean values of instantaneous DRE and RFE based on the pixel-level computation and the new method.

\begin{tabular}{lll}
\hline & $\begin{array}{l}\text { DRE }\left[\mathrm{W} \mathrm{m}^{-2}\right] \\
\text { Bias adjusted } \\
\text { (unadjusted) }\end{array}$ & $\begin{array}{l}\mathrm{RFE}\left[\mathrm{W} \mathrm{m} \mathrm{m}^{-2}\right. \\
\left.\mathrm{AOD}^{-1}\right] \\
\text { Bias adjusted } \\
\text { (unadjusted) }\end{array}$ \\
\hline $\begin{array}{l}\text { Pixel computation } \\
\text { New method }\end{array}$ & $6.6(5.92)$ & $56.0(50.3)$ \\
\hline
\end{tabular}

As previously mentioned, to estimate potential bias in CALIOP ACA AOD retrieval on our DRE computation, we carried out two sensitivity tests. We increased CALIOP AOD values by a factor of 1.5 in one test following Meyer et al. (2013) (hereafter referred to as "x1.5 test") and by a factor of 5 in another as suggested in Jethva et al. (2014) ("x5.0 test" hereafter). In both cases, we corrected the MODIS COD retrievals based on the scaled AOD. The regional and seasonal mean DRE of ACA increases, from the original value

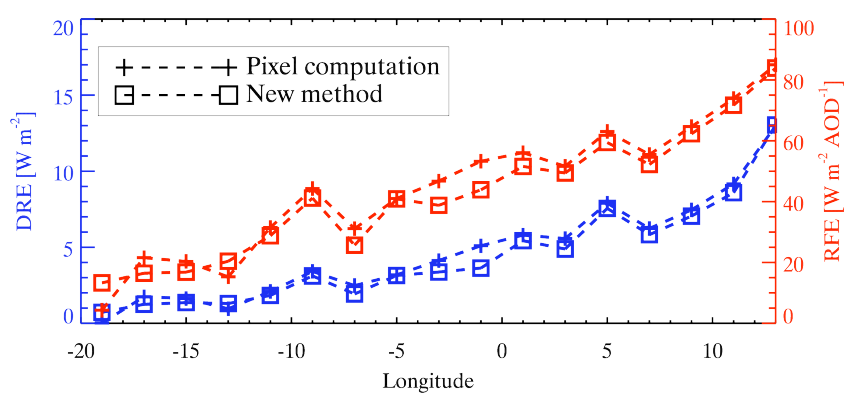

Figure 4. Meridional mean DRE and RFE for the region based on the results in Fig. 3. Lines with cross symbol correspond to pixel computations from Meyer et al. (2013). Lines with square symbol correspond to results based on the new method.

of 6.4 to $9.6 \mathrm{~W} \mathrm{~m}^{-2}$ in the $\mathrm{x} 1.5$ test and to $30.9 \mathrm{~W} \mathrm{~m}^{-2}$ in the $\mathrm{x} 5.0$ test. We have to note that this is a very rough estimate. Nevertheless, the DRE based on the x1.5 scaling of CALIOP AOD seems to agree reasonably with the value, $9.2 \pm 6.6 \mathrm{~W} \mathrm{~m}^{-2}$, reported in an independent study by Wilcox (Wilcox, 2012). Interestingly, the scaling of AOD has little impact on RFE in both cases $\left(53.1 \mathrm{~W} \mathrm{~m}^{-2} \mathrm{AOD}^{-1}\right.$ in the $\mathrm{x} 1.5$ case and $51.2 \mathrm{~W} \mathrm{~m}^{-2} \mathrm{AOD}^{-1}$ in the $\mathrm{x} 5.0$ case), which apparently suggests a near-linear relationship between DRE and AOD as also noted in Meyer et al. (2013) and Wilcox (2012) (see his Fig. 5).

In summary, as shown clearly in Figs. 3 and 4 and Table 2, the DRE inferred from our new method agrees very well with the pixel-level computations. Furthermore, the difference between the two methods is much smaller than, for example, the uncertainty associated with CALIOP retrieval biases.

It is worthwhile to clarify again that the results shown in Fig. 3 are seasonal mean instantaneous DRE at A-Train crossing time (13:30 LT) based on CALIOP above-cloud AOD and corrected Aqua-MODIS below-aerosol COD retrievals. Moreover, the aerosol model described in Meyer et al. (2013) is used in this study. All these factors should be considered when comparing the results in this study with those in other studies (e.g., Chand et al., 2009; Graaf et al., 2012; Wilcox, 2012). For example, Chand et al. (2009) used CALIOP in combination with Terra-MODIS observations to compute the DRE over the southeastern Atlantic region. It is known that low-clouds in this region have a strong diurnal cycle driven by solar cloud absorption (Bergman and Salby, 1996; Rozendaal et al., 1995; Wood et al., 2002). As a result the cloud properties observed by Terra MODIS can be significantly different from those observed by Aqua MODIS in this region, which could lead to different DRE even if the same method was used. 


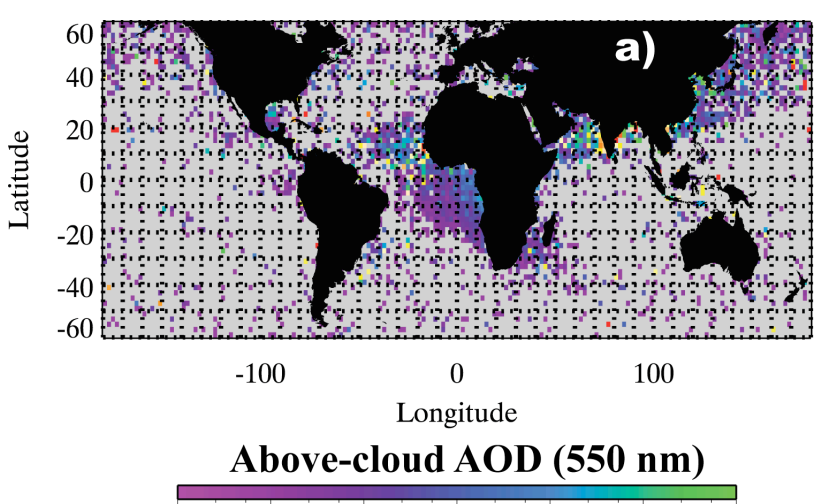

$\begin{array}{lllllll}0.010 & 0.019 & 0.037 & 0.071 & 0.136 & 0.261 & 0.500\end{array}$
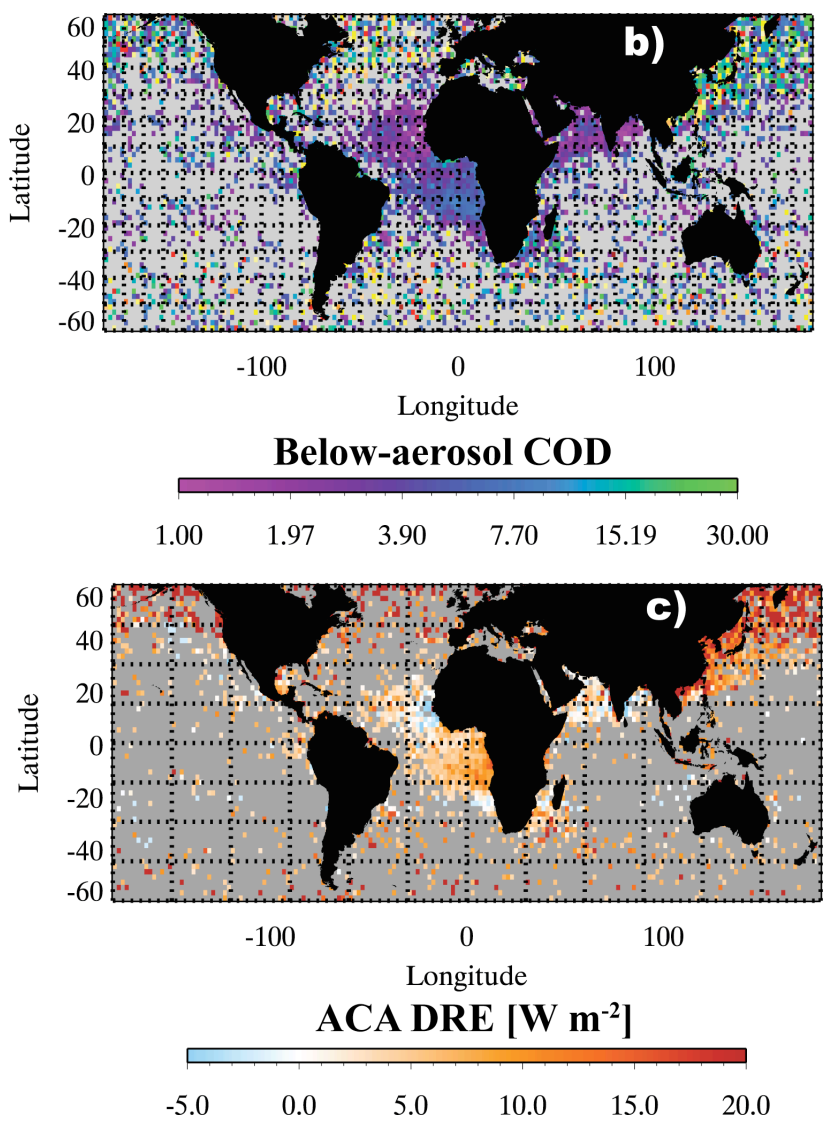

Figure 5. (a) Annual mean AOD (at $550 \mathrm{~nm}$ ) of above-cloud lightabsorbing aerosols (i.e., smoke and polluted dust) derived from 4 years (2007-2010) of the CALIOP $5 \mathrm{~km}$ aerosol and cloud layer products. (b) Annual mean below-aerosol COD derived from the MODIS daily level-3 COD-CTP joint histogram. (c) Annual mean instantaneous TOA DRE of above-cloud light-absorbing aerosols derived using the new method.

\section{Summary and discussion}

Recent advances in satellite-based remote sensing, in particular the launch of the space-borne lidar CALIOP, have provided an unprecedented opportunity for studying the radiative effects of ACA. However, the methodologies used in recent studies for computing the ACA DRE appear to be either oversimplified (e.g., Chand et al., 2009; Oikawa et al., 2013) or too cumbersome (e.g., Meyer et al., 2013). This paper describes a novel method recently developed for computing the shortwave DRE of above-cloud aerosols over ocean. Our method has several unique features compared to previous methods: (1) it takes subgrid-scale cloud and aerosol variation into account in DRE computations, similar to Meyer et al. (2013); (2) it treats the overlap of aerosol and cloud rigorously by utilizing the joint histogram of COD and CTP in the MODIS level-3 cloud product; (3) it relies on grid-level cloud statistics (i.e., COD-CTP joint histogram), instead of pixel-level products, and utilizes precomputed look-up tables for ACA DRE computations, thus making it much more efficient than pixel-level computations. As shown in Figs. 3 and 4 and Table 2, DRE computed using our method agrees well with the pixel-level computations of Meyer et al. (2013).

In addition to the southeastern Atlantic region, we have recently begun investigating the DRE of above-cloud lightabsorbing aerosols for the global ocean. Some preliminary results are shown in Fig. 5. We first derived the daily gridlevel statistics of above-cloud AOD and below-cloud COD, as well as the corresponding ACA DRE, using the method described above and then aggregated the daily means to annual mean. The temporal aggregation is weighted by the number of ACA pixels in each day during the period 20072010. For example, the annual mean ACA DRE in Fig. 5c is aggregated from the daily mean based on the following equation:

$$
\overline{\langle\mathrm{DRE}\rangle_{\mathrm{ACA}}}=\frac{\sum_{i} N_{i} \cdot\left\langle\mathrm{DRE}_{i}\right\rangle_{\mathrm{ACA}}}{\sum_{i} N_{i}}, \quad i=\text { day } 1,2,3 \ldots,
$$

where $\left\langle\mathrm{DRE}_{i}\right\rangle_{\mathrm{ACA}}$ is the spatially averaged instantaneous ACA DRE in each day averaged over ACA pixels, $N_{i}$ is the number of ACA pixels in the grid box in each day, and $\overline{\langle\mathrm{DRE}\rangle_{\mathrm{ACA}}}$ is the annual mean instantaneous ACA DRE shown in Fig. 5c. Figure 5a shows a global map of the annual mean $550 \mathrm{~nm}$ AOD of above-cloud smoke and polluted dust derived based on 4 years (2007-2010) of CALIOP aerosol and cloud layer products. Similar to Devasthale and Thomas (2011), we note several "hotspots" of ACA over the southeastern Atlantic, the east-central Atlantic off the western coast of Saharan Africa, the Arabian Sea, and the North Pacific Basin off the coast of eastern Asia. It is interesting to note that the ACA AOD over the east-central Atlantic and Arabian Sea is noticeably larger than that over the southeastern Atlantic and North Pacific Basin. Figure 5b shows the annual mean below-aerosol COD derived from the MODIS daily level-3 cloud product after the correction of above-cloud AOD contamination using the method described in Sect. 3. A notable feature in the figure is that the 
below-aerosol COD over the North Pacific Basin is significantly larger than that over other ACA regions. Figure $5 \mathrm{c}$ shows the annual mean shortwave DRE at TOA aggregated from daily values due to ACA smoke and polluted dust over the global ocean. It is intriguing to see that the DRE of ACA over the North Pacific Basin is significantly larger than that over the southeastern Atlantic, which is in turn larger than the DRE over the east-central Atlantic and the Arabian Sea. In fact, some negative DREs are observed in the latter two regions. This is probably due to the COD of below-aerosol clouds being too thin (Fig. $5 \mathrm{~b}$ ) over these regions to have significant radiative effect, so that the radiative effect of ACA is close to that of clear skies (i.e., negative). This is interesting because the above-cloud AOD over these regions is actually larger, while the below-aerosol COD over these regions is smaller, compared to their counterparts over the southeastern Atlantic and North Pacific Basin. Therefore, the preliminary results seem to suggest that the DRE variability of ACA is modulated by COD, rather than AOD, although it should be noted that we have focused only on the light-absorbing aerosols, i.e., smoke and polluted dust, and assumed the same narrowband scattering properties for them as in Meyer et al. (2013). Further research is needed to study the impact of aerosol type and scattering properties on the spatiotemporal variation of DRE on a global scale. Nevertheless, the preliminary results shown Fig. 5 clearly demonstrate the usefulness of our new method for global studies.

It should be noted that this study, and previous ones using CALIOP observations (e.g., Chand et al., 2008; Meyer et al., 2013; Oikawa et al., 2013), are limited by the capabilities of CALIOP. Arguably, some aerosols exist above every cloud. However, not all ACA can be detected by CALIOP due to its inherent limitations. Some ACAs are simply too optically thin to be detected, though their radiative effects are also expected to be small. Other situations may also be possible. For example, a confined aerosol layer has larger volume backscatter than a vertically stretched layer, even if the total aerosol amounts are the same, and therefore is more easily detected by CALIOP. Passive sensors, however, are less affected by the vertical distribution of ACA because they observe column-integrated scattering by aerosols. Recently, several novel techniques have been developed to detect and retrieve ACA properties using passive sensors. Waquet et al. (2009) developed a method based on multi-angular polarization measurements from POLDER to retrieve the AOD of above-cloud smoke. This method has recently been extended to include both smoke and dust aerosols (Waquet et al., 2013a). Most recently, Jethva et al. (2013) demonstrated the ability of a color ratio method to retrieve the above-cloud AOD based on MODIS multiple spectral cloud reflectance measurements. A review of the emerging satellite-based observations of above-cloud aerosols can be found in $\mathrm{Yu}$ and Zhang (2013). The capabilities and limitations of the passive techniques need to be systematically studied through intercomparisons and comparison with CALIOP observations, but they may provide a complementary perspective on ACA. Recall that passive imagers have much larger spatial coverage than CALIOP, which makes brute force calculations of the DRE at the pixel level computationally expensive. In this regard, our method satisfies the need for efficiency of ACA DRE computations based on passive imager retrievals.

As a final remark, we would like to point out that the ACA DRE discussed in this study is still a few steps away from the all-sky aerosol radiative effect ( $\left.\langle\mathrm{DRE}\rangle_{\text {all-sky }}\right)$. For a given grid box, the $\langle\mathrm{DRE}\rangle_{\text {all-sky }}$ can be decomposed into the sum of clear-sky and cloudy-sky DRE:

$$
\begin{aligned}
& \langle\mathrm{DRE}\rangle_{\text {all-sky }}= \\
& \quad\left(1-f_{\mathrm{c}}\right) \cdot\langle\mathrm{DRE}\rangle_{\text {clear }}+f_{\mathrm{c}} \cdot f_{\mathrm{ACA}} \cdot\langle\mathrm{DRE}\rangle_{\mathrm{ACA}},
\end{aligned}
$$

where $f_{\mathrm{c}}$ is the cloud fraction, $\langle\mathrm{DRE}\rangle_{\text {clear }}$ is the DRE averaged over the clear-sky portion of the grid box, $f_{\mathrm{ACA}}$ is the fraction of cloudy pixels with ACA detected by CALIOP or other sensors, and $\langle\mathrm{DRE}\rangle_{\mathrm{ACA}}$ is the DRE averaged over all ACA-containing pixels. It is important to note an implicit assumption made in Eq. (4); that is, when a distinct ACA layer is not detected, the DRE of ACA is zero. Different sensors (or different retrieval algorithms for the same sensor) may have different sensitivities to ACA and therefore provide different estimates of $f_{\mathrm{ACA}}$ and $\langle\mathrm{DRE}\rangle_{\mathrm{ACA}}$. For example, one sensor may only be able to retrieve ACA for optically thick clouds. This sensor would retrieve a larger $\langle\mathrm{DRE}\rangle_{\mathrm{ACA}}$, but a smaller $f_{\mathrm{ACA}}$, in comparison with another sensor capable of retrieving ACA for all clouds. Therefore, when comparing the ACA or all-sky DRE estimated based on different instruments or algorithms, it is important to compare both the $f_{\mathrm{ACA}}$ and $\langle\mathrm{DRE}\rangle_{\mathrm{ACA}}$ terms in Eq. (4).

Acknowledgements. We would like to acknowledge the Atmospheric and Environmental Research (AER), Inc. for developing the RRTM_SW model and making it publicly available. The CALIPSO data used in this study are from the NASA Langley Distributed Active Archive Center (DAAC). The MODIS data are from the NASA Level-1 and Atmosphere Achieve and Distribution System (LAADS). Z. Zhang acknowledges funding support from NASA through the New (Early Career) Investigator Program (NNX14AI35G) managed by Ming-Ying Wei. H. Yu was supported by NASA CALIPSO/CloudSat project under NNX14AB21G, managed by David Considine. L. Oreopoulos and D. Lee gratefully acknowledge support by NASA's Modeling Analysis and Prediction program.

Edited by: O. Torres 


\section{References}

Abel, S. J., Highwood, E. J., Haywood, J. M., and Stringer, M. A.: The direct radiative effect of biomass burning aerosols over southern Africa, Atmos. Chem. Phys., 5, 1999-2018, doi:10.5194/acp-5-1999-2005, 2005.

Ackerman, S., Strabala, K., Menzel, W., Frey, R., Moeller, C., and Gumley, L.: Discriminating clear sky from clouds with MODIS, J. Geophys. Res., 103, 32141-32157, 1998.

Bergman, J. W. and Salby, M. L.: Diurnal Variations of Cloud Cover and Their Relationship to Climatological Conditions, J. Climate, 9, 2802-2820, doi:10.1175/15200442(1996)009<2802:DVOCCA>2.0.CO;2, 1996.

Chand, D., Anderson, T. L., Wood, R., Charlson, R. J., Hu, Y., Liu, Z., and Vaughan, M.: Quantifying above-cloud aerosol using spaceborne lidar for improved understanding of cloudysky direct climate forcing, J. Geophys. Res., 113, D13206, doi:10.1029/2007JD009433, 2008.

Chand, D., Wood, R., Anderson, T. L., Satheesh, S. K., and Charlson, R. J.: Satellite-derived direct radiative effect of aerosols dependent on cloud cover, Nature Geoscience, 2(3), 181-184, doi:10.1038/ngeo437, 2009.

Clough, S. A., Shephard, M. W., Mlawer, E. J., Delamere, J. S., Iacono, M. J., Cady-Pereira, K., Boukabara, S., and Brown, P. D.: Atmospheric radiative transfer modeling: a summary of the AER codes, J. Quant. Spectr. Radiat. Trans., 91, 233-244, 2005.

Coddington, O. M., Pilewskie, P., Redemann, J., Platnick, S., Russell, P. B., Schmidt, K. S., Gore, W. J., Livingston, J., Wind, G., and Vukicevic, T.: Examining the impact of overlying aerosols on the retrieval of cloud optical properties from passive remote sensing, J. Geophys. Res., 115, D10211, doi:10.1029/2009JD012829, 2010.

Costantino, L. and Bréon, F.-M.: Aerosol indirect effect on warm clouds over South-East Atlantic, from co-located MODIS and CALIPSO observations, Atmos. Chem. Phys., 13, 69-88, doi:10.5194/acp-13-69-2013, 2013a.

Costantino, L. and Bréon, F.-M.: Satellite-based estimate of aerosol direct radiative effect over the South-East Atlantic, Atmos. Chem. Phys. Discuss., 13, 23295-23324, doi:10.5194/acpd-1323295-2013, 2013b.

Devasthale, A. and Thomas, M. A.: A global survey of aerosol-liquid water cloud overlap based on four years of CALIPSO-CALIOP data, Atmos. Chem. Phys., 11, 1143-1154, doi:10.5194/acp-11-1143-2011, 2011.

Eck, T. F., Holben, B. N., Ward, D. E., Mukelabai, M. M., Dubovik, O., Smirnov, A., Schafer, J. S., Hsu, N. C., Piketh, S. J., Queface, A., Roux, J. L., Swap, R. J., and Slutsker, I.: Variability of biomass burning aerosol optical characteristics in southern Africa during the SAFARI 2000 dry season campaign and a comparison of single scattering albedo estimates from radiometric measurements, J. Geophys. Res., 108, 8477, doi:10.1029/2002JD002321, 2003.

Graaf, M., Tilstra, L. G., Wang, P., and Stammes, P.: Retrieval of the aerosol direct radiative effect over clouds from spaceborne spectrometry, J. Geophys., 117, D07207, doi:10.1029/2011JD017160, 2012.

Hartmann, D., Holton, J., and Fu, Q.: The heat balance of the tropical tropopause, cirrus, and stratospheric dehydration, Geophys. Res. Lett., 28, 1969-1972, 2001.
Haywood, J. M., Osborne, S. R., and Abel, S. J.: The effect of overlying absorbing aerosol layers on remote sensing retrievals of cloud effective radius and cloud optical depth, Q. J. Roy. Meteorol. Soci., 130, 779-800, doi:10.1256/qj.03.100, 2004.

Hu, Y., Vaughan, M., Liu, Z., Lin, B., Yang, P., Flittner, D., Hunt, B., Kuehn, R., Huang, J., Wu, D., Rodier, S., Powell, K., Trepte, C., and Winker, D.: The depolarization - attenuated backscatter relation: CALIPSO lidar measurements vs. theory, Opt. Express, 15, 5327, doi:10.1364/OE.15.005327, 2007a.

Hu, Y., Vaughan, M., Liu, Z., Powell, K., and Rodier, S.: Retrieving Optical Depths and Lidar Ratios for Transparent Layers Above Opaque Water Clouds From CALIPSO Lidar Measurements, Geosci. Remote Sens. Lett., 4, 523-526, doi:10.1109/LGRS.2007.901085, 2007b.

Hubanks, P. A., King, M. D., Platnick, S., and Pincus, R.: MODIS atmosphere $\mathrm{L} 3$ gridded product algorithm theoretical basis document, Algorithm Theor. Basis Doc. ATBD-MOD, 30, 2008.

Iacono, M. J., Delamere, J. S., Mlawer, E. J., Shephard, M. W., Clough, S. A., and Collins, W. D.: Radiative forcing by long-lived greenhouse gases: Calculations with the AER radiative transfer models, J. Geophys. Res., 113, D13103, doi:10.1029/2008JD009944, 2008.

Ichoku, C., Remer, L. A., Kaufman, Y. J., Levy, R., Chu, D. A., Tanré, D., and Holben, B. N.: MODIS observation of aerosols and estimation of aerosol radiative forcing over southern Africa during SAFARI 2000, J. Geophys. Res., 108, 8499, doi:10.1029/2002JD002366, 2003.

Jethva, H., Torres, O., Remer, L. A., and Bhartia, P. K.: A color ratio method for simultaneous retrieval of aerosol and cloud optical thickness of above-cloud absorbing aerosols from passive sensors: Application to MODIS measurements, IEEE Trans. Geosci. Remote Sens., 51, 3862-3870, 2013.

Jethva, H., Torres, O., Waquet, F., Chand, D., and Hu, Y.: How do A-train sensors intercompare in the retrieval of above-cloud aerosol optical depth? A case study-based assessment, Geophys. Res. Lett., 41, 186-192, doi:10.1002/2013GL058405, 2014.

Kacenelenbogen, M., Vaughan, M. A., Redemann, J., Hoff, R. M., Rogers, R. R., Ferrare, R. A., Russell, P. B., Hostetler, C. A., Hair, J. W., and Holben, B. N.: An accuracy assessment of the CALIOP/CALIPSO version 2/version 3 daytime aerosol extinction product based on a detailed multi-sensor, multi-platform case study, Atmos. Chem. Phys., 11, 3981-4000, doi:10.5194/acp-11-3981-2011, 2011.

Kacenelenbogen, M., Redemann, J., Vaughan, M. A., Omar, A. H., Russell, P. B., Burton, S., Rogers, R. R., Ferrare, R. A., and Hostetler, C. A.: An evaluation of CALIOP/CALIPSO's aerosolabovecloud (AAC) detection and retrieval capability over North America, J. Geophys. Res.-Atmos., 19, 230-244, doi:10.1002/2013JD020178, 2013.

Keil, A. and Haywood, J. M.: Solar radiative forcing by biomass burning aerosol particles during SAFARI 2000: A case study based on measured aerosol and cloud properties, J. Geophys. Res., 108, 8467, doi:10.1029/2002JD002315, 2003.

King, M. D., Platnick, S., Menzel, W. P., Ackerman, S. A., and Hubanks, P. A.: Spatial and Temporal Distribution of Clouds Observed by MODIS Onboard the Terra and Aqua Satellites, IEEE Trans. Geosci. Remote Sens., 51, 3826-3852, doi:10.1109/TGRS.2012.2227333, 2013. 
Kistler, R., Collins, W., Saha, S., White, G., Woollen, J., Kalnay, E., Chelliah, M., Ebisuzaki, W., Kanamitsu, M., Kousky, V., van den Dool, H., Jenne, R., and Fiorino, M.: The NCEP-NCAR 50-Year Reanalysis: Monthly Means CD-ROM and Documentation, Bull. Am. Meteorol. Soc., 82, 247-267, doi:10.1175/15200477(2001)082<0247:TNNYRM>2.3.CO;2, 2001.

Levy, R. C., Remer, L. A., Tanre, D., Mattoo, S., and Kaufman, Y. J.: Algorithm for remote sensing of tropospheric aerosol over dark targets from MODIS: Collections 005 and 051: Revision 2, MODIS Algorithm Theoretical Basis Document for the MOD04_L2 Product, 2009.

Liu, Z., Vaughan, M., Winker, D., Kittaka, C., Getzewich, B., Kuehn, R., Omar, A., Powell, K., Trepte, C., and Hostetler, C.: The CALIPSOLidar Cloud and Aerosol Discrimination: Version 2 Algorithm and Initial Assessment of Performance, J. Atmos. Ocean. Technol., 26, 1198-1213, doi:10.1175/2009JTECHA1229.1, 2009.

Liu, Z., Winker, D. M., Omar, A. H., Vaughan, M., Kar, J., Trepte, C. R., and Hu, Y.: Evaluation of CALIOP 532-nm AOD over Clouds, AGU Fall Meeting 2013, 2013.

Menzel, P., Frey, R., Baum, B., and Zhang, H.: Cloud Top Properties and Cloud Phase Algorithm Theoretical Basis Document, 2006.

Menzel, W., Smith, W., and Stewart, T.: Improved Cloud Motion Wind Vector and Altitude Assignment Using VAS, J. Appl. Meteorol., 22, 377-384, 1983.

Meyer, K., Platnick, S., Oreopoulos, L., and Lee, D.: Estimating the direct radiative effect of absorbing aerosols overlying marine boundary layer clouds in the southeast Atlantic using MODIS and CALIOP, J. Geophys. Res.-Atmos., 118, 48014815, doi:10.1002/jgrd.50449, 2013.

Min, M. and Zhang, Z.: On the influence of cloud fraction diurnal cycle and sub-grid cloud optical thickness variability on all-sky direct aerosol radiative forcing, J. Quant. Spectr. Radiat., 142, 25-36, doi:10.1016/j.jqsrt.2014.03.014, 2014.

Myhre, G., Berntsen, T. K., Haywood, J. M., Sundet, J. K., Holben, B. N., Johnsrud, M., and Stordal, F.: Modeling the solar radiative impact of aerosols from biomass burning during the Southern African Regional Science Initiative (SAFARI-2000) experiment, J. Geophys. Res., 108(D13), 8501, doi:10.1029/2002JD002313, 2003.

Nakajima, T. and King, M.: Determination of the optical thickness and effective particle radius of clouds, J. Atmos. Sci., 47, 18781893, 1990.

Oikawa, E., Nakajima, T., Inoue, T., and Winker, D.: A study of the shortwave direct aerosol forcing using ESSP/CALIPSO observation and GCM simulation, J. Geophys. Res., 118, 3687-3708, doi:10.1002/jgrd.50227, 2013.

Omar, A. H., Winker, D. M., Vaughan, M. A., Hu, Y., Trepte, C. R., Ferrare, R. A., Lee, K.-P., Hostetler, C. A., Kittaka, C., and Rogers, R. R.: The CALIPSO automated aerosol classification and lidar ratio selection algorithm, J. Atmos. Ocean. Technol., 26, 1994-2014, 2009.

Oreopoulos, L., Cahalan, R. F., and Platnick, S.: The Plane-Parallel Albedo Bias of Liquid Clouds from MODIS Observations, J. Climate, 20, 5114-5125, doi:10.1175/JCLI4305.1, 2007.

Platnick, S., King, M., Ackerman, S., Menzel, W., Baum, B., Riedi, J., and Frey, R.: The MODIS cloud products: algorithms and examples from Terra, Geosci. Remote Sens., 41, 459-473, 2003.
Rossow, W. B. and Schiffer, R. A.: Advances in Understanding Clouds from ISCCP, Bull. Am. Meteorol. Soc., 80, 2261-2287, doi:10.1175/1520-0477(1999)080<2261:AIUCFI>2.0.CO;2, 1999.

Rozendaal, M. A., Leovy, C. B., and Klein, S. A.: An Observational Study of Diurnal Variations of Marine Stratiform Cloud, J. Climate, 8, 1795-1809, 1995.

Schulz, M., Textor, C., Kinne, S., Balkanski, Y., Bauer, S., Berntsen, T., Berglen, T., Boucher, O., Dentener, F., Guibert, S., Isaksen, I. S. A., Iversen, T., Koch, D., Kirkevåg, A., Liu, X., Montanaro, V., Myhre, G., Penner, J. E., Pitari, G., Reddy, S., Seland, $\varnothing$., Stier, P., and Takemura, T.: Radiative forcing by aerosols as derived from the AeroCom present-day and pre-industrial simulations, Atmos. Chem. Phys., 6, 5225-5246, doi:10.5194/acp-65225-2006, 2006.

Schulz, J., Albert, P., Behr, H.-D., Caprion, D., Deneke, H., Dewitte, S., Dürr, B., Fuchs, P., Gratzki, A., Hechler, P., Hollmann, R., Johnston, S., Karlsson, K.-G., Manninen, T., Müller, R., Reuter, M., Riihelä, A., Roebeling, R., Selbach, N., Tetzlaff, A., Thomas, W., Werscheck, M., Wolters, E., and Zelenka, A.: Operational climate monitoring from space: the EUMETSAT Satellite Application Facility on Climate Monitoring (CM-SAF), Atmos. Chem. Phys., 9, 1687-1709, doi:10.5194/acp-9-1687-2009, 2009.

Stier, P., Schutgens, N. A. J., Bellouin, N., Bian, H., Boucher, O., Chin, M., Ghan, S., Huneeus, N., Kinne, S., Lin, G., Ma, X., Myhre, G., Penner, J. E., Randles, C. A., Samset, B., Schulz, M., Takemura, T., Yu, F., Yu, H., and Zhou, C.: Host model uncertainties in aerosol radiative forcing estimates: results from the AeroCom Prescribed intercomparison study, Atmos. Chem. Phys., 13, 3245-3270, doi:10.5194/acp-13-3245-2013, 2013.

Torres, O., Jethva, H., and Bhartia, P. K.: Retrieval of Aerosol Optical Depth above Clouds from OMI Observations: Sensitivity Analysis and Case Studies, 69, 1037-1053, doi:10.1175/JAS-D11-0130.1, 2012.

Torres, O., Ahn, C., and Chen, Z.: Improvements to the OMI nearUV aerosol algorithm using A-train CALIOP and AIRS observations, Atmos. Meas. Tech., 6, 3257-3270, doi:10.5194/amt-63257-2013, 2013.

Twomey, S.: Atmospheric aerosols, Elsevier Scientific Publishing Co., New York, NY, 1977.

Vaughan, M. A., Powell, K. A., Winker, D. M., Hostetler, C. A., Kuehn, R. E., Hunt, W. H., Getzewich, B. J., Young, S. A., Liu, Z., and McGill, M. J.: Fully Automated Detection of Cloud and Aerosol Layers in the CALIPSO Lidar Measurements, J. Atmos. Ocean. Technol., 26, 2034-2050, doi:10.1175/2009JTECHA1228.1, 2009.

Waquet, F., Riedi, J., Labonnote, L. C., Goloub, P., Cairns, B., Deuzé, J. L., and Tanre, D.: Aerosol Remote Sensing over Clouds Using A-Train Observations, J. Atmos. Sci., 66, 2468-2480, doi:10.1175/2009JAS3026.1, 2009.

Waquet, F., Cornet, C., Deuzé, J.-L., Dubovik, O., Ducos, F., Goloub, P., Herman, M., Lapyonok, T., Labonnote, L. C., Riedi, J., Tanré, D., Thieuleux, F., and Vanbauce, C.: Retrieval of aerosol microphysical and optical properties above liquid clouds from POLDER/PARASOL polarization measurements, Atmos. Meas. Tech., 6, 991-1016, doi:10.5194/amt-6-991-2013, 2013a.

Waquet, F., Peers, F., Ducos, F., Goloub, P., Platnick, S., Riedi, J., Tanré, D. and Thieuleux, F.: Global analysis of aerosol 
properties above clouds, Geophys. Res. Lett., 40, 5809-5814, doi:10.1002/2013GL057482, 2013b.

Wilcox, E. M.: Stratocumulus cloud thickening beneath layers of absorbing smoke aerosol, Atmos. Chem. Phys., 10, 1176911777, doi:10.5194/acp-10-11769-2010, 2010.

Wilcox, E. M.: Direct and semi-direct radiative forcing of smoke aerosols over clouds, Atmos. Chem. Phys., 12, 139-149, doi:10.5194/acp-12-139-2012, 2012.

Winker, D. M., Tackett, J. L., Getzewich, B. J., Liu, Z., Vaughan, M. A., and Rogers, R. R.: The global 3-D distribution of tropospheric aerosols as characterized by CALIOP, Atmos. Chem. Phys., 13, 3345-3361, doi:10.5194/acp-13-3345-2013, 2013.

Winker, D. M., Vaughan, M. A., Omar, A., Hu, Y., Powell, K. A., Liu, Z., Hunt, W. H., and Young, S. A.: Overview of the CALIPSO mission and CALIOP data processing algorithms, J. Atmos. Oceanic Technol., 26, 2310-2323, 2009.

Wiscombe, W. J.: Improved Mie scattering algorithms, Appl. Optics, 19, 1505-1509, 1980.

Wood, R., Bretherton, C. S., and Hartmann, D. L.: Diurnal cycle of liquid water path over the subtropical and tropical oceans, Geophys. Res. Lett., 29, 2092, doi:10.1029/2002GL015371, 2002.

Young, S. A. and Vaughan, M. A.: The Retrieval of Profiles of Particulate Extinction from Cloud-Aerosol Lidar Infrared Pathfinder Satellite Observations (CALIPSO) Data: Algorithm Description, J. Atmos. Oceanic Technol., 26, 1105-1119, doi:doi:10.1175/2008JTECHA1221.1, 2008.
Yu, H. and Zhang, Z.: New Directions: Emerging satellite observations of above-cloud aerosols and direct radiative forcing, Atmos. Environ., 72, 36-40, doi:10.1016/j.atmosenv.2013.02.017, 2013.

Yu, H., Kaufman, Y. J., Chin, M., Feingold, G., Remer, L. A., Anderson, T. L., Balkanski, Y., Bellouin, N., Boucher, O., Christopher, S., DeCola, P., Kahn, R., Koch, D., Loeb, N., Reddy, M. S., Schulz, M., Takemura, T., and Zhou, M.: A review of measurement-based assessments of the aerosol direct radiative effect and forcing, Atmos. Chem. Phys., 6, 613-666, doi:10.5194/acp-6-613-2006, 2006.

Zelinka, M. D., Klein, S. A., and Hartmann, D. L.: Computing and partitioning cloud feedbacks using cloud property histograms, Part I: Cloud radiative kernels, J. Climate, 25, 37153735, doi:10.1175/JCLI-D-11-00248.1, 2012.

Zhang, Z.: On the sensitivity of cloud effective radius retrieval based on spectral method to bi-modal droplet size distribution: A semianalytical model, J. Quant. Spectr. Radiat. Trans., 129, 79-88, doi:10.1016/j.jqsrt.2013.05.033, 2013.

Zhang, Z. and Platnick, S.: An assessment of differences between cloud effective particle radius retrievals for marine water clouds from three MODIS spectral bands, J. Geophys. Res., 116, D20215, doi:10.1029/2011JD016216, 2011.

Zhang, Z., Ackerman, A. S., Feingold, G., Platnick, S., Pincus, R., and Xue, H.: Effects of cloud horizontal inhomogeneity and drizzle on remote sensing of cloud droplet effective radius: Case studies based on large-eddy simulations, J. Geophys. Res., 117, D19208, doi:10.1029/2012JD017655, 2012. 